\title{
Good dragon bad dragon
}

Here are two dragons. One is a good dragon and he looks after his teeth well. They are healthy teeth. One is a bad dragon and he does not look after his teeth. His teeth are not healthy. This picture is for you to colour in and to remind you to look after your teeth.

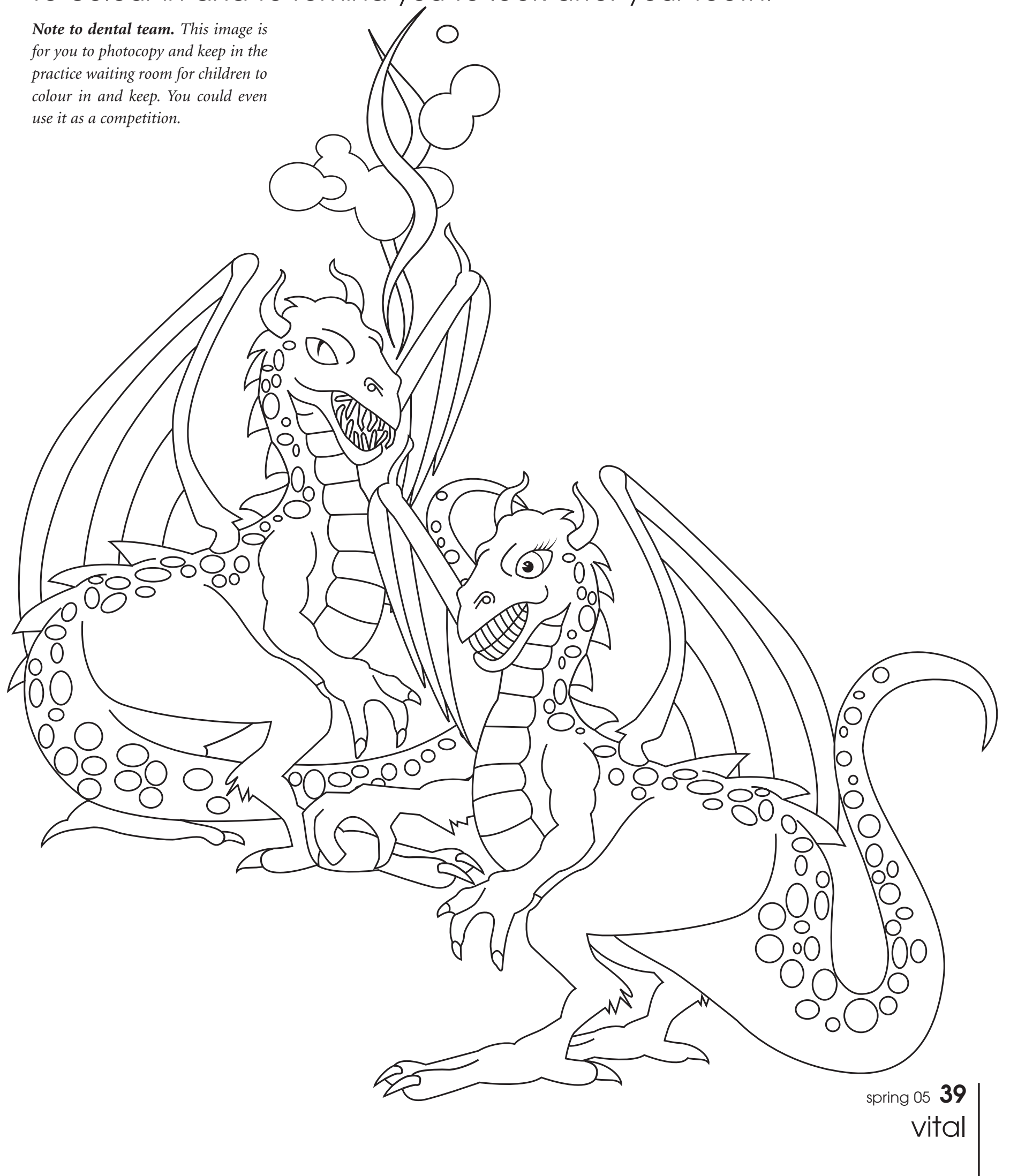

